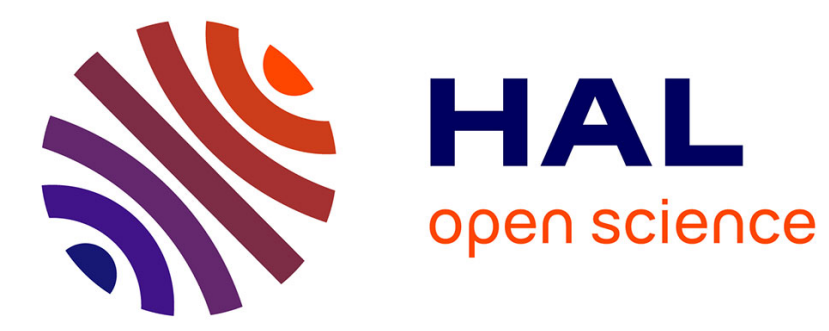

\title{
Electric Load Profile Non-intrusive Analysis to Guide Energy Efficient Behavior for Residential Clients
}

Etta Grover-Silva, Elena Magliaro, Johanna Le Conte

\section{To cite this version:}

Etta Grover-Silva, Elena Magliaro, Johanna Le Conte. Electric Load Profile Non-intrusive Analysis to Guide Energy Efficient Behavior for Residential Clients. 2019 IEEE PES Innovative Smart Grid Technologies Europe (ISGT-Europe), Sep 2019, Bucharest, Romania. pp.1-5, 10.1109/ISGTEurope.2019.8905431 . hal-02618225

\section{HAL Id: hal-02618225}

https://hal-mines-paristech.archives-ouvertes.fr/hal-02618225

Submitted on 25 May 2020

HAL is a multi-disciplinary open access archive for the deposit and dissemination of scientific research documents, whether they are published or not. The documents may come from teaching and research institutions in France or abroad, or from public or private research centers.
L'archive ouverte pluridisciplinaire HAL, est destinée au dépôt et à la diffusion de documents scientifiques de niveau recherche, publiés ou non, émanant des établissements d'enseignement et de recherche français ou étrangers, des laboratoires publics ou privés. 


\section{Electric load profile non-intrusive analysis to guide energy efficient behavior for residential clients}

\author{
$1^{\text {st }}$ Etta Grover-Silva \\ Eco CO2 \\ Nanterre, France \\ etta.grover-silva@ecoco2.com
}

\author{
$2^{\text {nd }}$ Elena Magliaro \\ Eco $\mathrm{CO} 2$ \\ Nanterre, France \\ elena.magliaro@ecoco2.com
}

\author{
$3^{\text {rd }}$ Johanna Le Conte \\ Eco $\mathrm{CO} 2$ \\ Nanterre, France \\ johanna.leconte@ecoco2.com
}

\begin{abstract}
In the context of the energy transition with ambitious goals about reducing electric energy use, residential energy consumption is a large part of total energy use and has a high potential for energy savings. Recently, deployment of smart meters have enabled residential load profile data to be more easily accessible. Therefore, services are emerging to better inform residential customers about their energy use. These services have been highly effective to reduce energy use when feedback is given about appliance specific energy use. This paper presents a simple and effective algorithm to use non-intrusive load monitoring analysis combined with a questionnaire to provide quick appliance specific energy use feedback to residential customers. The algorithm is only based on the historical energy use, does not require significant computational capacity, respects the confidentiality of clients with no data sharing involved and can be deployed offline if the client does not have access to internet. This makes this type of algorithm widely applicable and informative for residential customers.
\end{abstract}

Index Terms-non-intrusive load monitoring, demand response

\section{INTRODUCTION}

Residential buildings use a high percentage of total energy use in developed countries around the world: 25\% in France, $25 \%$ in Germany, $19 \%$ in Spain and 26\% in the UK [7]. Smart meter deployment has recently allowed for increased visibility of electric load profile data for residential customers. Load profile data allows for a new understanding of when and how energy is used in residential houses. Increasing concern about global warming, ambitious political goals related to energy security and reducing $\mathrm{CO} 2$ emissions are driving a new market of services that use this data now more easily accessible for residential clients.

Often residential clients are unaware of how to reduce their energy use at home. Informing users about their energy use and strategies to encourage energy efficient behavior can help reduce their energy use and energy bills. An awareness raising program has been put in place by the company Eco $\mathrm{CO} 2$ in the context of a public tender in France put forth by ADEME related to a funding mechanism called Investissement d'avenir. This awareness raising program aims to educate residential clients about their energy use and provides feedback to encourage energy efficient behavior. A tablet is available for users to observe their energy use and possible ways to decrease their consumption.
Inneficient behavioural habits can contribute to an excessive amount of energy use that is unnecessary for the comfort of building inhabitants. The gap between the design energy use of building and the actual energy use is called the operational energy efficiency gap. This gap can be up to $100 \%$ implying that a building will use twice as much energy as stated by the design requirements [2]. Informing inhabitants of their energy use and how to reduce it is therefore essential to guaranteeing energy efficient buildings.

Total energy use of the household has been proven to not be the most effective way to encourage energy efficient behavior. More detailed information about the appliances present in the household and suggestions for specific actions to take is much more effective in reducing energy use. As stated in [1], several studies show that real-time feedback about appliance specific energy use results in the most energy savings. This may require detailed information about the appliances present in the household or an energy audit which can be expensive and time consuming. These intrusive strategies are not widely applicable. Therefore, many non-intrusive strategies are also presented in the literature.

Non-intrusive methods often called Non-intrusive Load Monitoring (NILM) use electric load profile data to partition the total energy use into individual appliance categories. Smart meter data for residential customers is typically available with a $1 \mathrm{~min}$ to $30 \mathrm{~min}$ resolution depending on the data collection system. As stated in [1], this resolution of data allows primarily for differentiating three main categories of electric load: temperature correlated load, continuous loads and time-dependent loads. With a resolution of $1 \mathrm{~min}$ to $1 \mathrm{~s}$, it is possible to extract the top 10 appliance types including refrigeration, ACs, heaters, pool pumps, washers, dryers, etc. [1]. Detailed machine learning algorithms have been explored to partition data with a high frequency $(1 \mathrm{~Hz})$. These algorithms include Graph Signal Processing, Hidden Markov Models, or deep neural networks. The algorithms are either event based or non event based, supervised or nonsupervised [8]. However, this type of high frequency data is not available through the current smart meter technology being deployed in Europe for example. These machine learning type algorithms can also require high computational capacity and a big data type infrastructure such as cloud computing. In order to develop a solution that is widely deployable with minimal 
requirements of the information technology architecture, a simpler algorithm is preferable.

This paper presents an effective and simplified algorithm to partition a total electrical load profile into four main categories. These four categories are then further separated by applying statistical studies of typical uses of final devices in order to provide an estimation of energy use per device. This strategy requires very minimal computational capacity, can be applied to a single user and is based on historical use instead of requiring analytics across a large group of users. Therefore, the solution is widely applicable and can be deployed individually for a single household. This avoids difficult questions about data confidentiality and the security of a cloud computing solution. The non-intrusive method avoids high costs of individually metering different appliances within the home. This non-intrusive analysis of the total electric load profile provides a cost effective solution to communicate more pertinent suggestions to clients on how to reduce their energy use.

Building modeling strategies can be classified into two main methodologies, top-down modeling or bottom-up modeling. The main advantage of top-down modeling is that very minimal information is needed about the building. Global trends of the load profile in relation to exogenous variables such as outside temperatures can be extracted and used to make conclusions about the temperature dependent loads of a building. Bottom-up modeling techniques are based on the physical characteristics of a building and can be much more precise in comparison to top-down modeling. However, a significant amount of time is required to collect a detailed inventory of appliances, envelope characteristics and operational schedules. Due to the necessity to develop a methodology that can be widely applicable, a pure bottom-up modeling technique is not feasible.

A hybrid approach is developed in this paper attempting to use the advantages of both methods. Limited information about the household is gathered through a questionnaire about the building energy systems and operational set points. Secondly, a top-down approach is used to identify active and non-active periods as well as the correlation with temperature of these two categories. This end-use decomposition algorithm is applied to a group of residential clients in order to inform end-users about their energy use and improve their behavioral energy efficiency.

\section{Methodology}

This paper presents a hybrid approach based on statistical studies combined with detailed consumption profile analysis for calibration and load trending. Multiple benchmark studies are collected and compared to calculate the appropriate statistical values of target end-use devices such as ventilation, refrigeration, domestic hot water use, cooking loads, washing machines, lighting and multimedia. A top-down analysis is then performed on the total electric load profile to identify four main categories: inactive loads, active loads and their correlation with temperature or not. An active load is defined
TABLE I

LOAD PROFILE ANALYSIS CATEGORIES

\begin{tabular}{l|l}
\hline \hline Load category & Appliance categories \\
\hline \hline $\begin{array}{l}\text { Temperature correlated } \\
\text { active load }\end{array}$ & $\begin{array}{l}\text { Heating, AC, fans, thermal comfort } \\
\text { devices }\end{array}$ \\
\hline $\begin{array}{l}\text { Temperature correlated in- } \\
\text { active load }\end{array}$ & $\begin{array}{l}\text { Heating, AC, fans, thermal comfort } \\
\text { devices }\end{array}$ \\
\hline Non-correlated active load & $\begin{array}{l}\text { cooking, multimedia, lighting, } \\
\text { washing machines }\end{array}$ \\
\hline $\begin{array}{l}\text { Non-correlated inactive } \\
\text { load }\end{array}$ & $\begin{array}{l}\text { refrigeration, ventilation, domestic } \\
\text { hot water heater, phantom loads }\end{array}$ \\
\hline
\end{tabular}

as a load controlled by an end-user. An inactive load is classified by a device that automatically turns on or off and is not manually controlled by an end-user. A detailed analysis of the total electric load profile is performed to identify the energy use associated with each of these four categories. The load profile categories are then decomposed further based on the end-use device categories and information provided by a questionnaire such as the number of people, surface area, etc. For example, an end-uses device such as a ventilation system is assigned to a load profile category such as non-correlated temperature inactive load. The four main load categories and their associated possible contributing devices are listed in table I.

\section{A. Bottom-up method}

Multiple studies have been performed in an attempt to quantify the annual consumption of household appliances [3], [4], [6], [9]-[11]. These studies allow for the estimation of the magnitude of the energy use associated with each appliance in comparison to the total household energy use. Multiple factors contribute to the large range of annual energy consumption present for a majority of appliances presented in these studies. These factors include the number of people in a household, the surface area of a household, the age of the appliances, etc. Therefore, questionnaire information such as surface area and number of people are used to estimate a percentage of the overall category associated with each type of appliance. The value of the energy used for each appliance category is therefore dependent on the global energy use categories calculated by the top-down method.

\section{B. Top-down method}

Analysis of the load profile data is used to extract more precise characteristics of the building energy usage and energy usage habits. Characteristics concerning four main categories are extracted: active and non-active periods as well as the temperature correlated part of these two categories.

1) Inactive load vs active load: The inactive or constant load of a household is detected by analyzing the magnitude of the values present during a day period as well as the variance of these values. The average value of a given timestep is calculated with 10 minutes electric load data by equation 1 .

$$
h_{m, h}=\frac{\sum_{n=1}^{N} C_{n}}{N}
$$


Where $h_{m, h}$ is the average value of energy used during the 10 minute periods, $N$ is the number of data points within the hour and $C_{n}$ is the energy use during the 10 minute period $n$. To quantify the activity of turning on an off appliances during a given timestep, the first order difference of a 10 minutes load profile is calculated. The $90^{t h}$ percentile of the first order difference values is calculated for each hour. This $90^{t h}$ percentile allows for the quantification of activity that has occurred within the hour period based on 10 minutes load profile data. The equation used to calculate this indicator is shown in equation 2 .

$$
\begin{array}{r}
Q_{f}(90)=x: \operatorname{Pr}(X \leq x)=90 \\
X=\left|C_{n}-C_{n-1}\right| \\
n \subset N
\end{array}
$$

Where $Q_{f}(90)$ is the $90^{\text {th }}$ percentile of all values during the hour period, $X$ is the first order difference of each data point during the hour period and $C_{n-1}$ is the energy use for the timestemp $n-1$. The mean value and the $90^{t h}$ percentile are then associated for each hour and a K-means clustering technique is used to identify three groups of the twodimensional data. The physical sense of these three categories is related to inactive loads, small appliance use during active periods or large appliance use active periods. This clustering technique allows the identification of two main categories: active period and non-active period.

2) Temperature sensitive loads: The temperature sensitive part of the load is evaluated by analyzing the inactive and active daily energy use in comparison to degree days per day. Degree days are often used in building energy analysis to quantify heating and cooling loads. Degree days represent the total amount of time during a day where the temperature is above or below a certain threshold that would require air conditioning loads to attain the desired inside temperature set point. The heating degree days and the cooling degree days are calculated with equation 3 and equation 4 respectively using a temperature data timeseries with a 3 hour resolution [5].

$$
\begin{aligned}
d d_{\text {heat }} & =\frac{\sum_{n=1}^{N}\left(18-T_{n}\right)}{N} \\
d d_{\text {cool }} & =\frac{\sum_{n=1}^{N}\left(T_{n}-21\right)}{N}
\end{aligned}
$$

Where $d d_{\text {heat }}$ is the heating degree days, $T_{n}$ is the temperature at time $n$ and $d d_{\text {cool }}$ is the cooling degree days. Total daily energy use for the active and non-active category are analyzed separately. An initial analysis is completed to compare the heating degree days and the cooling degree days to determine weather the dwelling should be in heating or cooling mode. The linear correlation between the normalized daily energy use the the normalized daily degree days is then calculated attempting to use two different models. First, a piece wise linear fit is calculated with a forced first segment slope of 0 . Secondly a linear regressing is fitted to all data points. The root mean squared error is then compared for the two fitted models to determine the final model. These models are calculated with equation 5 and equation 6 respectively.

$$
\begin{array}{rr}
y_{i}=y_{0} & x<x_{0} \\
y_{i}=\beta x_{i}+\left(y_{0}-\beta x_{0}\right) & x \geq x_{0} \\
y_{i}=\beta x_{i}+\epsilon &
\end{array}
$$

Where $y_{0}$ is the value of the first segment of the temperature coorelation curve with a slope of $0, \beta$ is the slope of the temperature coorelated segment with an $y$ intercept of $y_{0}-\beta x_{0}$ and $\epsilon$ is the $y$ intercept of the simple linear regression equation. If a correlation is found in either the active or inactive energy load, the integral of the linear regression is evaluated to determine the percentage of the load category that is temperature coorelated.

\section{CASE STUdY}

The data used for this study was collected through the services offered by the company Eco CO2. The data is anonymized for the purpose of this paper. The data is collected through sensors that are capable of reading and transmitting the main electric meter measurements. The data used for this study is composed of a 100 households. The 100 households are analyzed with the decomposition algorithm for every week for a one year period.

\section{RESUlts}

The mathematical method used to identify the inactive load was effective. The clustering method allowed for the identification of hour periods where the overall value and relative variation of the 10 minute data is low. A detailed example of two users with a curve showing the separation of the inactive periods and the active periods can be seen in figure 1 .

As shown in figure 1, the periods of innactivity are identified. The two profiles analyzed have more or less variation during the weekly period, however, the algorithm is effective in both cases. This analysis allows for the separation of loads that fall into the category of active loads such as domestic hot water use or multi-media devices as opposed to inactive loads such as refrigeration or ventilation systems. This also allows for the analysis of the temperature corelation of the inactive load and the active load separately. The separation before analyzing temperature dependence can give insight into wheather the household leaves their heating system on during unoccupied periods. An example of the final result showed to the end user can be seen in figure 3 .

The final decomposition results are displayed to the client to inform them of their energy consumption for the previous week. Historical values can also be found and information such as a percentage increase or decrease for each individual appliance is provided. This allows users to compare their own behaviour of last week in contrast with their historical use. 

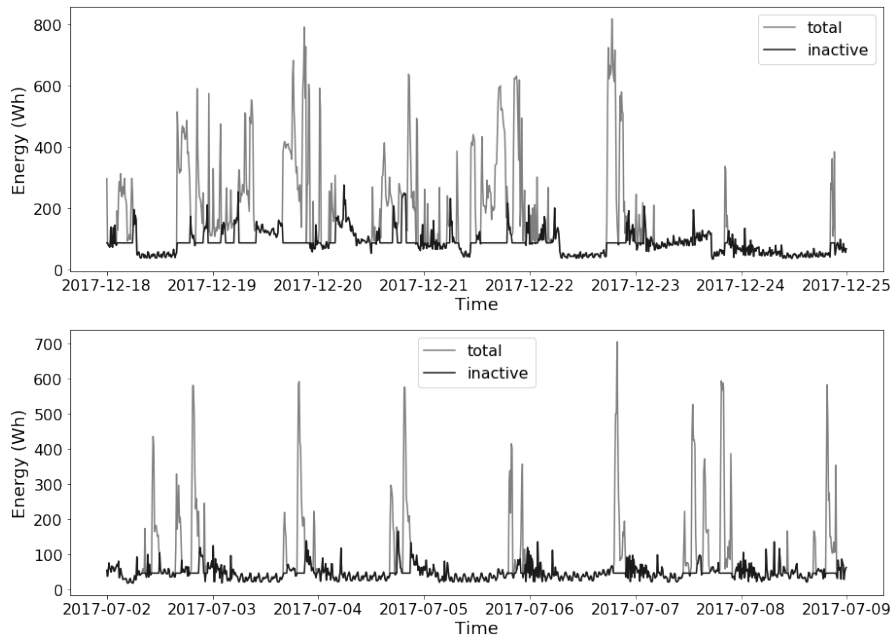

Fig. 1. Inactive and active loads identified for end user 1 in an example week in December (top) and June (bottom)
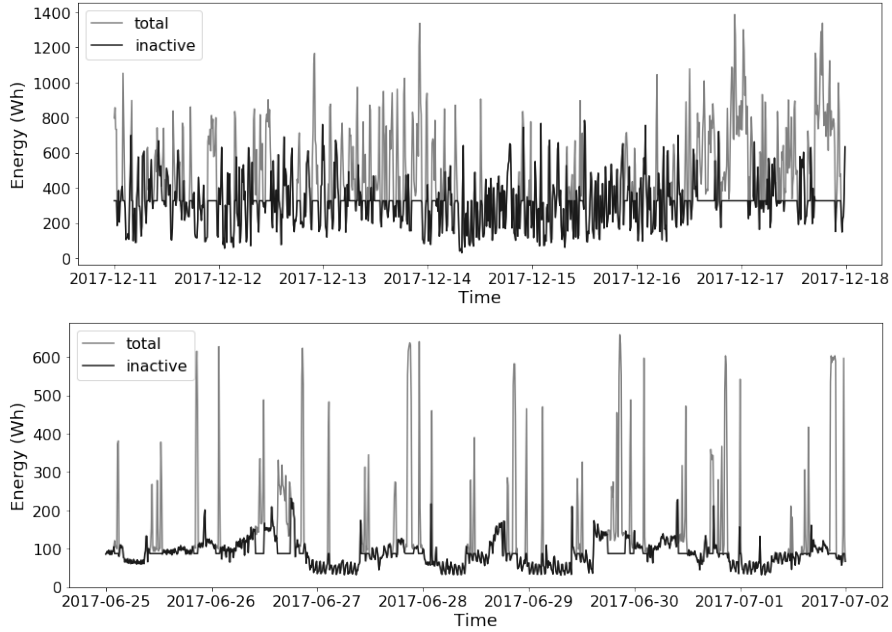

Fig. 2. Inactive and active loads identified for end user 2 in an example week in December (top) and June (bottom)
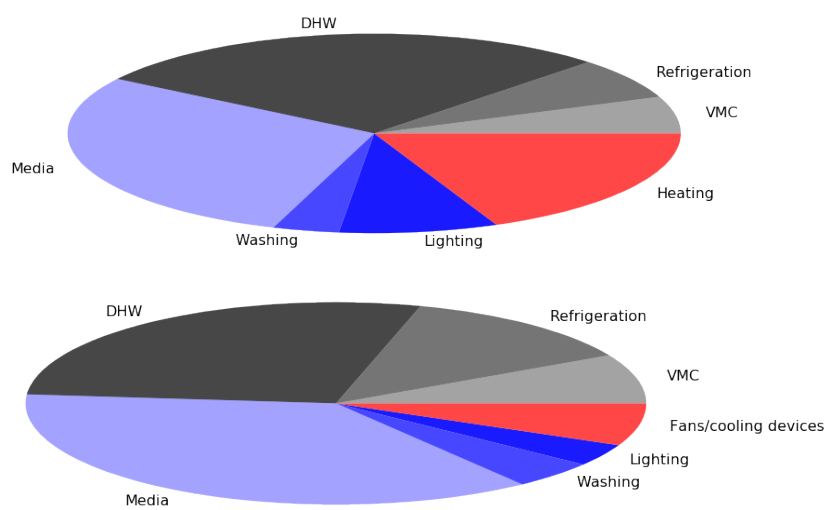

Fig. 3. Final decomposition results showed to end user 1 for December (top) and June (bottom)
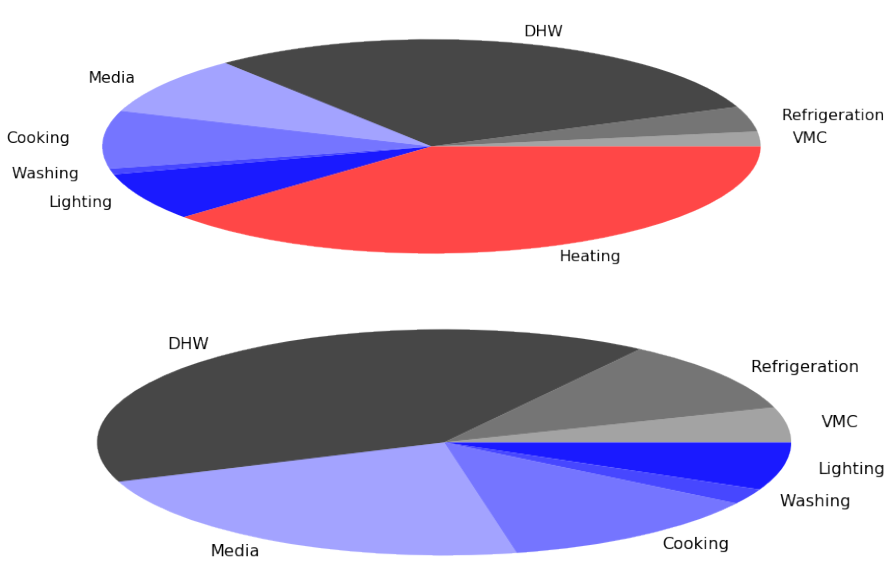

Fig. 4. Final decomposition results showed to end user 2 for December (top) and June (bottom)

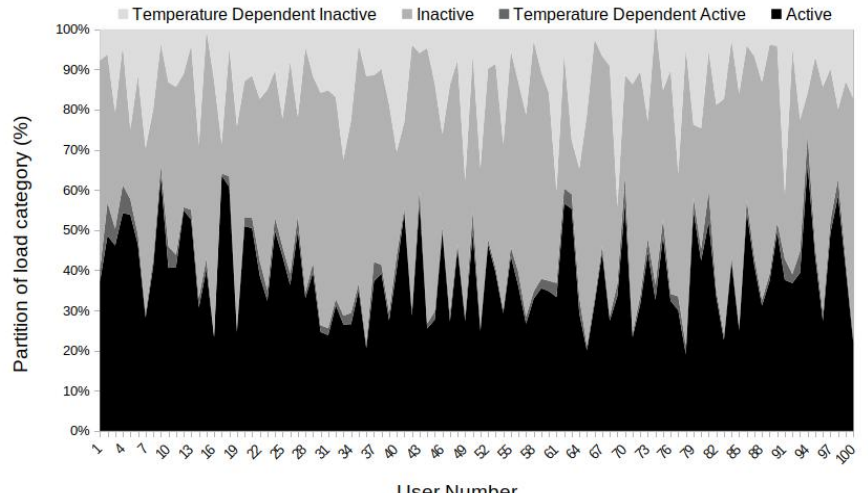

Fig. 5. Restuls for 100 users in relation to the percentage of the annual consumption in each of the four main decomposition categories

Results of all 100 users for a whole year period was calculated to identify the overall trend of temperature dependent inactive and active loads. The final yearly results can be seen in figure 5 .

Of the hundred users analyzed, $38 \%$ did not have electric heating and 50\% did not have electric domestic hot water. Therefore, during the decomposition algorithm, these end-use appliances were not considered. If all users are considered, the temperature corelated part of the total energy use varies between users from $1.25 \%$ and $38 \%$ with an average of $12 \%$. It is also interesting to see that a large part of the temperature dependent load is identified in the inactive load category and not in the active load category. This implies that a majority of households leave their heating systems on even during innocupied periods. The final decomposition for all users during the year period can be seen in figure 6

The proportion of each appliance for individual clients can vary significantly depending on if the clients have electric heating and electric domestic hot water production. In general, electric heating and electric domestic hot water heating are the highest consumption appliances. 


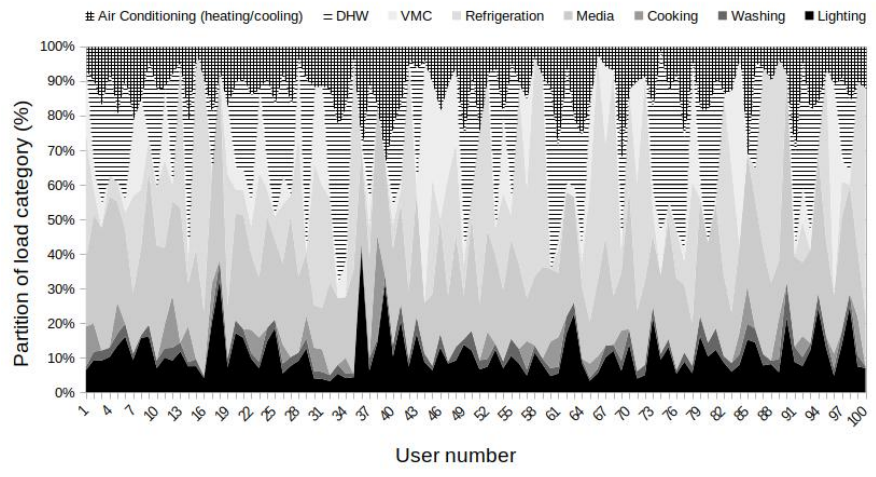

Fig. 6. Restuls for 100 users in relation to the percentage of the annual consumption in each of the appliance categories

\section{CONCLUSION}

This paper has presented a simple yet effective decomposition technique that is widely applicable for the analysis of individual electric load data for each user. It is also compatible with the type and resolution of data available through the masive deployment of smart meters. It does not require high computational power or any sort of cloud computing and therefore could even be deployed locally with no sharing of data if a client is concerned about their data privacy. The solution can also be deployed locally for clients with no internet connection. As data privacy increases to be a concern, this solution allows for users to learn and understand details about their own electric energy use even if they are not interested in sharing their data or allowing their data to be used in a larger context. The algorithm has been demonstrated to be effective for 100 example households.

\section{REFERENCES}

[1] K. Carrie Armel, Abhay Gupta, Gireesh Shrimali, and Adrian Albert. Is disaggregation the holy grail of energy efficiency? the case of electricity. Energy Policy, 52:213-234, 2013.

[2] Fredrik Berg, Anne-Cathrine Flyen, sne Lund Godbolt, and Tor Brostrm. User-driven energy efficiency in historic buildings: A review. Journal of Cultural Heritage, 28:188 - 195, 2017.

[3] Enertech. Campagne de mesures de l'eclairage dans 100 logements en france. Technical report, Electricite de France et Agence de l'Environnement et de la Maitrise de l'Energie, 2004.

[4] Enertech. Consommation des principaux appareils electrodomestiques: Appareils mnagers et clairage. Technical report, 2008.

[5] Meteo France. Donnees synop essentielles omm, 2019.

[6] T. Kreitz. Campagne de mesures des appareils de production de froid, des appareils de lavage et de la climatisation. Technical report, ADEME, 2016.

[7] E. Mata, A. Sasic Kalagasidis, and F. Johnsson. Building-stock aggregation through archetype buildings: France, germany, spain and the uk. Building and Environment, 81:270-282, June 2014.

[8] Million Abayneh Mengistu, Awet Abraha Girmay, Chirstian Camarda, Andrea Acquaviva, and Edoardo Patti. A cloud-based on-line disaggregation algorithm for home appliance loads. IEEE Transactions on Smart Grid, 2018.

[9] Selectra. Estimer sa consommation d'electricite en kwh et en euros. Technical report, 2019.

[10] Olivier Sidler. Maitrise de la demande d'electricite: Etude experimentale des appareils de suisson, de froid menager et de sechage dans 100 logements. Technical report, Commision des communqutes europeennes, Electricit de France et Agence de l'Environnement et de lq Mqitrise de l'Energie, 1999.
[11] Olivier Sidler. Connaissance et maitrise des usages specifiques de l'electricite dans le secteur residentiel. Technical report, Enertech, 2009. 